\title{
RHINOLOGY
}

\section{Effect of rhinophototherapy on nasal congestion in patients with seasonal allergic rhinitis}

\author{
Effetto della rinofototerapia sulla congestione nasale nei pazienti con rinite allergica \\ stagionale
}

\author{
Elif Karali ${ }^{1}$, Akif Gunes ${ }^{1}$, Ahmet Ural ${ }^{1}$, Isa Akin ${ }^{1}$, Emine Ozsari², Oya Kalaycioglu ${ }^{3}$ \\ ${ }^{1}$ Department of Otorhinolaryngology, Bolu Abant Izzet Baysal University Medical Faculty, Bolu, Turkey; ${ }^{2}$ Department of Pulmonology \\ Bolu Abant Izzet Baysal University Medical Faculty, Bolu, Turkey; ${ }^{3}$ Department of Bioistatistics and Medical Information, Bolu Abant \\ Izzet Baysal University Medical Faculty, Bolu, Turkey
}

\section{SUMMARY}

Objective. The aim of the present study was to objectively and subjectively evaluate the effects of adding rhinophototherapy to intranasal beclomethasone dipropionate to treat nasal congestion in patients with seasonal allergic rhinitis.

Method. Seventy-five seasonal allergic rhinitis patients were randomly divided into two groups. Patients in Group 1 received intranasal beclomethasone dipropionate for two weeks and patients in Group 2 had rhinophototherapy added to the same medical therapy as Group 1. The effectiveness of treatments was evaluated with the Rhinoconjunctivitis Quality of Life Questionnaire (RQLQ), Nasal Obstruction Symptom Evaluation scale (NOSE) questionnaires and active anterior rhinomanometry.

Results. After treatment, significant improvement was observed in Group 2 vs Group 1 in terms of RQLQ ( $p=0.011)$ and NOSE $(p=0.001)$ scores. In Group 2, significant differences were observed between before and after treatment for inspiratory total nasal resistance $(\mathrm{p}=0.004)$. However, no significant differences vs. baseline were observed in Group 1.

Conclusion. Our study shows that adding intranasal phototherapy with a combination of UVA, UVB and visible light therapy to nasal beclomethasone dipropionate treatment objectively improves nasal patency in patients with seasonal allergic rhinitis.

KEY WORDS: rhinophototherapy, nasal congestion, seasonal allergic rhinitis, rhinomanometry, total nasal resistance

\section{RIASSUNTO}

Obiettivo. Valutare in maniera oggettiva e soggettiva gli effetti del dipropionato beclometasone con l'aggiunta della rhinofototerapia nel trattamento della rinite allergica stagionale. Metodi. Settantacinque pazienti affetti da rinire allergica stagionale sono stati randomizzati in due gruppi. Gruppo 1, trattamento con dipropionato beclometasone per due settimane. Gruppo 2, rinofototerapia in aggiunta al trattamento del gruppo 1. L'efficacia dei trattamenti è stata valutata con il Rhinoconjunctivitis Quality of Life Questionnaire (RQLQ), il Nasal Obstruction Symptom Evaluation scale (NOSE) e la rinomanometria attiva anteriore. Risultati. È risultata una differenza statisticamente significativa fra il gruppo 2 e 1 in termini di RQLQ $(p=0,011)$ e NOSE $(p=0,001)$. Nel gruppo 2 sono risultate delle differenze nelle resistenze nasali $(p=0,004)$ prima e dopo il trattamento e nessuna differenza statisticamente significativa nel gruppo 1.

Conclusioni. L'aggiunta della fototerapia intranasale con UVA, UVB e luce bianca migliora $i$ sintomi nei pazienti con rinite allergica stagionale.

PAROLE CHIAVE: rinofototerapia, congestione nasale, rinite allergica stagionale, rinomanometria, resistenza nasale totale

\section{Introduction}

Allergic rhinitis (AR) is a common inflammatory disease that affects $10 \%$ -
Received: June 5, 2020

Accepted: October 8, 2020

Correspondence

Elif Karali

Department of Otorhinolaryngology, Bolu Abant Izzet Baysal University Medical Faculty, Bolu, Turkey

Tel. +90 3742534656. Fax +90 3742534615

E-mail: elifkarali8181@gmail.com

Funding

None.

\section{Conflict of interest}

The Authors declare no conflict of interest.

How to cite this article: Karali E, Gunes A, Ural A, et al. Effect of rhinophototherapy on nasal congestion in patients with seasonal allergic rhinitis. Acta Otorhinolaryngol Ital 2021;41:151158. https://doi.org/10.14639/0392-100X-N0907

() Società Italiana di Otorinolaringoiatria e Chirurgia Cervico-Facciale

\section{(c) (1) (\$) $\odot$}

This is an open access article distributed in accordance with the CC-BY-NC-ND (Creative Commons Attribution-NonCommercial-NoDerivatives 4.0 International) license. The article can be used by giving appropriate credit and mentioning the license, but only for non-commercial purposes and only in the original version. For further information: https:// creativecommons.org/licenses/by-nc-nd/4.0/deed.en 
$40 \%$ of the population worldwide ${ }^{1}$. Common symptoms of AR are sneezing, itching, rhinorrhoea, nasal congestion, erythema and tearing eyes. Nasal congestion is usually the most disturbing symptom experienced by AR patients and negatively affects the quality of life ${ }^{2}$. Many different methods are used in medical treatment of AR. Intranasal corticosteroids (INCS) are recommended by international guidelines as first-line drugs for patients with AR. INCS are considered to have high efficacy in controlling nasal symptoms in AR ${ }^{1,3}$. In particular, nasal beclomethasone dipropionate has been shown to have positive effects on the severity of nasal symptoms and quality of life. It is also effective in terms of decreasing eosinophils and lymphocytes in nasal mucosa and is well-tolerated ${ }^{4,5}$.

In some patients, symptoms cannot be reduced by medical treatment alone; in others, medical treatment options may be limited for a variety of reasons. Alternative treatment modalities are thus required in these patients. Phototherapy, which has been used to treat inflammatory skin diseases, has become an alternative treatment option for AR in recent years. Intranasal phototherapy in patients with AR has been reported to have similar effects to those seen in dermatological diseases ${ }^{6}$. The efficacy of the combination of UV-B, UV-A and high-intensity visible light (Rhinolight ${ }^{\circledR}$ ) in seasonal allergic rhinitis (SAR) has been demonstrated in double-blind, placebo-controlled randomised clinical trials ${ }^{7-9}$. The therapeutic features of phototherapy are mostly attributed to its local immunomodulatory and immunosuppressive effects. Phototherapy inhibits the synthesis and release of proinflammatory mediators from eosinophils, mast cells, basophils and T cells ${ }^{8}$.

Previous studies have reported an improvement in nasal congestion with rhinophototherapy in patients with AR; however, the number of studies that have included objective evaluations is small ${ }^{10}$. The aim of the present study was to objectively and subjectively evaluate the effects of adding rhinophototherapy to intranasal beclomethasone dipropionate to treat nasal congestion in patients with SAR.

\section{Materials and methods}

\section{Study design}

The study protocol was approved by the local ethics committee in accordance with the Helsinki declaration (13.12.2018 n. 2018/239). Both written and verbal informed consents were obtained from all participants in the study.

This prospective randomised controlled study was conducted between March and November 2019. Seventy-five patients were included, each of whom had SAR for at least two years. The study was carried out during the pollen season. Diagnosis of SAR was based on the 2016 ARIA
Table I. Allergen variance of the group 1and the group 2 according to skin prick test (SPT).

\begin{tabular}{lcc} 
& \multicolumn{2}{c}{ Treatment group } \\
Allergen & Group 1 & Group 2 \\
& $(\mathrm{N}=33)$ & $(\mathrm{N}=31)$ \\
Grass mix & $23(69.7 \%)$ & $21(67.7 \%)$ \\
Tree mix & $15(45.5 \%)$ & $13(41.9 \%)$ \\
\hline
\end{tabular}

Group 1: Intranasal beclomethasone dipropionate therapy. Group 2: Rhinophototherapy with intranasal beclomethasone dipropionate therapy.

criteria ${ }^{1}$. In addition to clinical symptoms, diagnosis was confirmed by a positive skin prick test performed using inhalant allergen extracts (Dermatophagoides pteronyssinus, Dermatophagoides farinea, grass mix, trees mix, dog, cat, Cladosporium Herbarum, Aspergillus Fumigatus, Piume mix) (ALK, Hørsholm, Denmark). Histamine (10 mg/mL) was used as a positive control and saline as a negative control. All patients had a positive skin prick test for tree and/ or grass pollen allergens (wheal diameter $\geq 3 \mathrm{~mm}$ ) (Tab. I). Patients with hypersensitivity to allergens other than pollen were excluded from the study.

All otorhinolaryngological physical examinations, including endoscopic examination, were performed.

Exclusion criteria were: significant nasal structural abnormalities such as nasal polyp, nasal septal deviation, nasopharyngeal pathology, upper and lower acute respiratory infection within two weeks, asthma and pregnancy. All patients in the study refrained from the following treatments for the duration indicated in the weeks before the start of the study: systemic steroids for four weeks prior; nasal steroids for two weeks prior; antihistamines for one week prior; and nasal decongestant drugs for the last three days prior.

Patients were divided into two randomly selected groups in a 1:1 ratio, using a simple randomisation system for different treatment regimens. Simple randomisation was achieved with a sequence of random numbers from a computer-generated sequence. A random number list was generated in Microsoft Office Excel 2016.

Intranasal beclomethasone dipropionate (200 mcg/day) was given to Group $1(\mathrm{n}=33)$ for two weeks, and rhinophototherapy (5\% UVB, 25\% UVA, 70\% visible light three times weekly for two weeks) was added to the intranasal beclomethasone dipropionate $(200 \mathrm{mcg} /$ day $)$ treatment in Group 2 ( $\mathrm{n}=31)$.

Intranasal phototherapy was performed with the same device (Rhinolight III; Rhinolight Ltd, Szeged, Hungary) by the same examiner. Each nostril was irradiated with increasing doses three times per week for two weeks. Treatments lasted 2-3 minutes. The highest dose administered while gradually increasing doses was $2.4 \mathrm{~J} / \mathrm{cm}^{2}$ given after an initial dose of $1.6 \mathrm{~J} / \mathrm{cm}^{2}$ was applied for two minutes. 
The effectiveness of treatment was evaluated by the RQLQ and NOSE questionnaires, and active anterior rhinomanometry. The Rhinoconjunctivitis Quality of Life Questionnaire (RQLQ) and Nasal Obstruction Symptom Evaluation scale (NOSE) questionnaire were applied before and after treatment together with rhinomanometry.

\section{Efficacy of treatment}

The RQLQ is a 28-question diagnostic tool used to evaluate adult patients (17 to 70 years old) with rhinoconjunctivitis ${ }^{11}$. RQLQ covers the following seven domains: activity limitations; sleep problems; nose symptoms; eye symptoms; non-nose/eye symptoms; practical problems; and emotional function. Each item is graded on a sevenpoint scale $(0=$ not impaired at all; $6=$ severely impaired $)$ and the score is the average of 28 responses. The Nasal Obstruction Symptom Evaluation (NOSE) scale is a frequently used quality of life questionnaire ${ }^{12}$ which specifically focuses on nasal congestion before and after treatment ${ }^{13}$. The NOSE scale is composed of five questions concerning the severity of nasal obstruction. Each item is evaluated using a Likert scale $(0=$ not a problem to $4=$ severe problem); these answers are summed and then multiplied by five, for a total final NOSE score within a range of 0 to 100 .

Nasal airflow and nasal airway resistance were measured objectively with active anterior rhinomanometry. In this study, measurements were made with an SRE 2000 Rhinometer (RhinoMetrics, Lynge, Denmark) device. All measurements were performed without decongestion under the same standard conditions. Airway resistances were measured with right, left and total airflows in all patients. The evaluation was carried out at a fixed 150 Pascal pressure agreed upon by the European Rhinomanometry Standardization Committee in 1984. Left (RL) and right (RR) unilateral nasal resistance values were calculated according to Ohm's law ${ }^{14}$. Total nasal resistance was calculated using the formula $\mathrm{RL} \times \mathrm{RR} / \mathrm{RL} \times+\mathrm{RR}$.

\section{Statistical analysis}

Data are presented as means \pm SD. Repeated-measures ANOVA was used to assess treatment effects and changes at the end of the treatment, as well as the variation of mean values before and after treatment within the treatment groups. The differences between treatment groups at different stages were further evaluated Student's t-tests. HolmBonferroni correction was employed to adjust for multiple testing. The results were assessed at a level of $p<0.05$. The analyses were performed using the Statistical Package for Social Sciences 25.0 for Windows (SPSS Inc., Chicago, Illinois, USA). Figures were generated using the ggplot2 package in $\mathrm{R}$ version 3.6.1 ( $\mathrm{R}$ Development Core Team, 2010; www.R-project.org) ${ }^{15}$.

\section{Results}

Eleven patients (five in Group 1 and six in Group 2) dropped out for either poor compliance or upper respiratory tract infections. Thus, 64 patients (33 in Group 1 and 31 in Group 2) completed the study. Data from the dropouts was not included in the evaluation (Fig. 1).

These two patient groups were very homogeneous in terms of age, gender and clinical findings. Demographic data are shown in Table II. Both groups had significant improvements from baseline total RQLQ and NOSE scores after treatment. At the same time, the treatment by time interaction was found to be significant, which suggests that the patterns of change in total RQLQ and NOSE

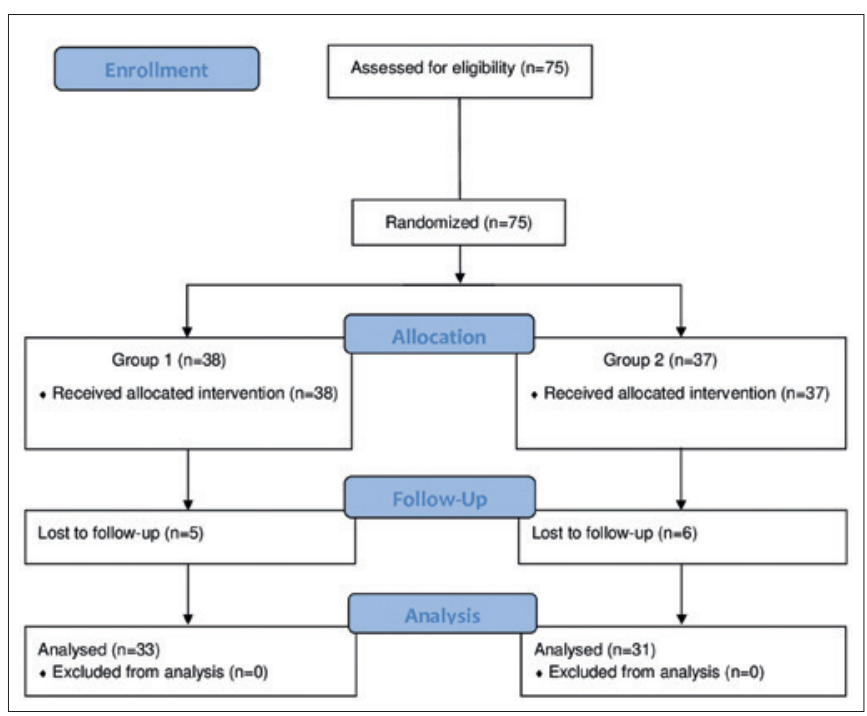

Figure 1. The Consolidated Standards of Reporting Trials (CONSORT) flowchart.

Group 1, intranasal beclomethasone dipropionate therapy Group 2, Rhinophototherapy with intranasal beclomethasone dipropionate therapy.

Table II. Demographic data for treatment groups.

\begin{tabular}{lccc}
\multicolumn{4}{c}{ Treatment group } \\
Group 1 & $\begin{array}{l}\text { Group 2 } \\
(\mathbf{n = 3 1 )}\end{array}$ & $\mathbf{p}$ \\
Age & $32.45 \pm 12.27$ & $28.84 \pm 10.68$ & $0.215^{\mathrm{a}}$ \\
Gender & & & $0.479^{\mathrm{b}}$ \\
Female & $23(69.7 \%)$ & $19(1.3 \%)$ & \\
Male & $10(30.3 \%)$ & $12(37.5 \%)$ & \\
\hline
\end{tabular}

Mean $\pm S D$, or $n(\%) ;{ }^{a}$ Independent samples t-test; ${ }^{b}$ Pearson's chi-square test. Group 1: Intranasal beclomethasone dipropionate therapy. Group 2: Rhinophototherapy with intranasal beclomethasone dipropionate therapy. 


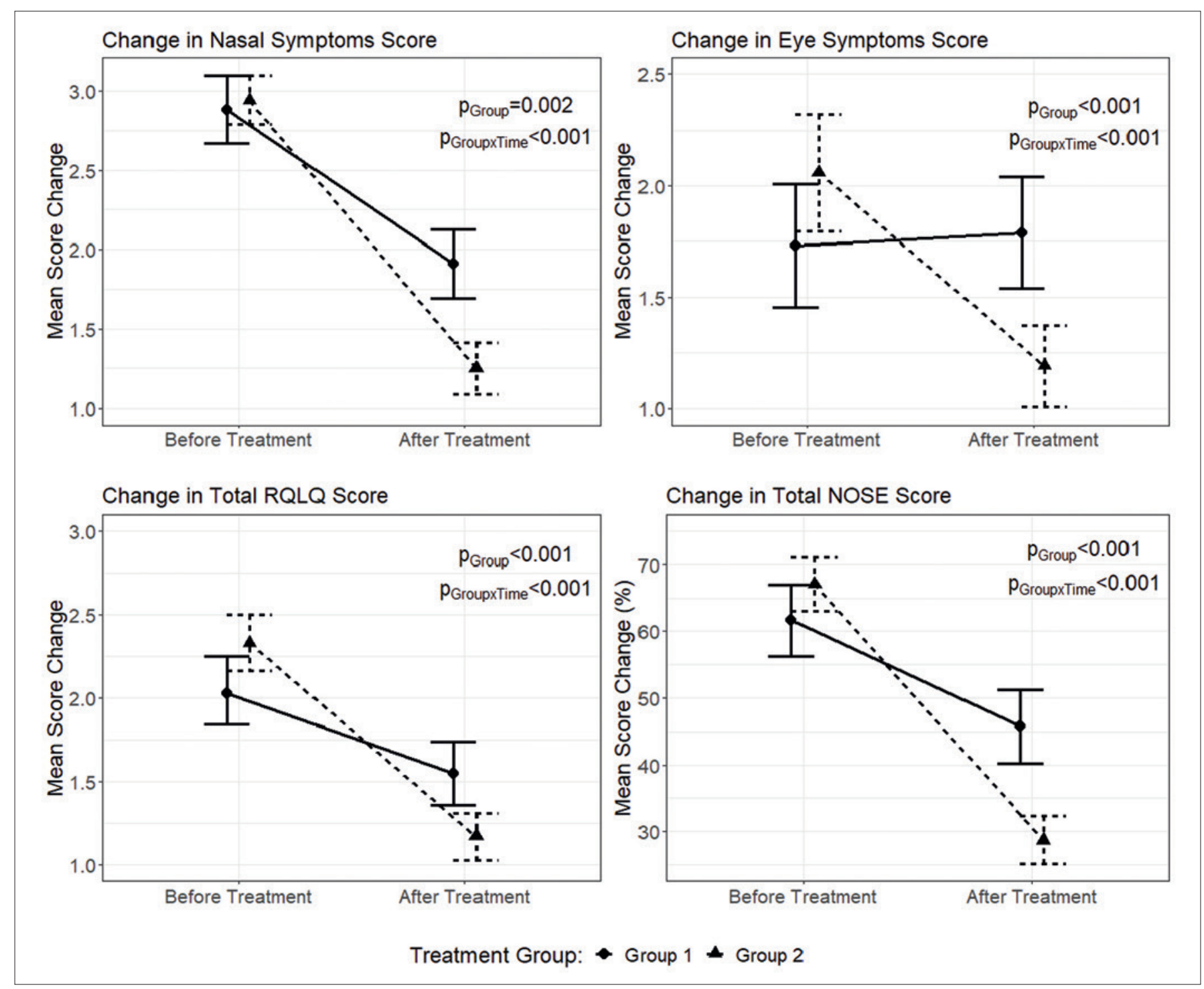

Figure 2. Changes in nasal symptoms, eye symptoms, total RQLQ and NOSE scores after treatment, compared to before treatment (figures represent mean \pm SEM. p-values obtained from two-way repeated measures ANOVA).

scores were different in Group 1 and Group $2(\mathrm{p}<0.001)$ (Fig. 2).

When total RQLQ scores were considered, no significant differences were observed between groups before treatment $(p=0.102)$. However, the differences between groups after treatment were significant $(\mathrm{p}=0.011)$. Although total RQLQ scores decreased after treatment in both groups, the reduction in total RQLQ scores after treatment was larger in Group 2 compared to Group 1 [mean differences: -1.16 (95\%CI: $-1.45,-0.87)$ vs -0.48 (95\%CI: $-0.69,-0.26)]$.

When the effect of treatments was assessed for the RQLQ domain scores, the overall group effect was significant for nasal $(p=0.002)$ and eye $(p<0.001)$ symptoms (Fig. 2$)$. In addition, a significant group by time interaction for these RQLQ domain scores implies that the changes in scores over time were different depending on the treatment group. Further comparisons of treatment groups for nasal and eye symptoms scores showed significant differences after treatment $(\mathrm{p}=0.001, \mathrm{p}=0.009)$, while there was no difference between groups before treatment ( $\mathrm{p}=0.753, \mathrm{p}=0.224$ ).

When RQLQ domains were compared within groups, both treatment groups showed significant improvements from baseline RQLQ domain scores after treatment $(\mathrm{p}<0.01)$, except for the eye symptoms score in Group $1(\mathrm{p}=0.625)$ (Tab. III). When the change in eye symptoms scores were examined, no significant improvements in eye symptoms were observed in Group 1 after treatment (Fig. 2). 
Table III. Comparison of RQLQ (Rhinoconjunctivitis Quality of Life Questionnaire) domains before and after treatment.

\begin{tabular}{|c|c|c|c|c|}
\hline RQLQ Domain & Treatment Group & $\begin{array}{l}\text { Before treatment } \\
\quad(\text { mean } \pm S D)\end{array}$ & $\begin{array}{l}\text { After treatment } \\
(\text { mean } \pm S D)\end{array}$ & $p^{a}$ \\
\hline \multirow[t]{3}{*}{ Sleep } & Group 1 & $2.06 \pm 1.14$ & $1.55 \pm 0.94$ & 0.001 \\
\hline & Group 2 & $2.59 \pm 0.95$ & $1.25 \pm 0.67$ & $<0.001$ \\
\hline & $p^{b}$ & 0.045 & 0.149 & \\
\hline \multirow[t]{3}{*}{ Non-nose/eye symptoms } & Group 1 & $2.06 \pm 1.30$ & $1.73 \pm 1.21$ & 0.006 \\
\hline & Group 2 & $1.88 \pm 1.13$ & $1.22 \pm 0.91$ & $<0.001$ \\
\hline & $p^{b}$ & 0.541 & 0.060 & \\
\hline \multirow[t]{3}{*}{ Practical problems } & Group 1 & $2.09 \pm 1.16$ & $1.61 \pm 1.09$ & 0.001 \\
\hline & Group 2 & $2.22 \pm 0.75$ & $1.19 \pm 0.78$ & $<0.001$ \\
\hline & $p^{b}$ & 0.600 & 0.080 & \\
\hline \multirow[t]{3}{*}{ Nasal symptoms } & Group 1 & $2.88 \pm 0.86$ & $1.91 \pm 0.88$ & $<0.001$ \\
\hline & Group 2 & $2.94 \pm 0.62$ & $1.25 \pm 0.67$ & $<0.001$ \\
\hline & $p^{b}$ & 0.753 & 0.001 & \\
\hline \multirow[t]{3}{*}{ Eye symptoms } & Group 1 & $1.73 \pm 1.13$ & $1.79 \pm 1.02$ & 0.625 \\
\hline & Group 2 & $2.06 \pm 1.08$ & $1.19 \pm 0.74$ & $<0.001$ \\
\hline & $p^{b}$ & 0.224 & 0.009 & \\
\hline \multirow[t]{3}{*}{ Limited activity } & Group 1 & $1.67 \pm 0.99$ & $1.18 \pm 0.95$ & 0.007 \\
\hline & Group 2 & $2.31 \pm 0.97$ & $1.13 \pm 0.75$ & $<0.001$ \\
\hline & $p^{b}$ & 0.010 & 0.790 & \\
\hline \multirow[t]{3}{*}{ Emotional functions } & Group 1 & $1.73 \pm 1.07$ & $1.12 \pm 0.93$ & 0.002 \\
\hline & Group 2 & $2.31 \pm 0.86$ & $1.00 \pm 0.80$ & $<0.001$ \\
\hline & $p^{b}$ & 0.018 & 0.576 & \\
\hline \multirow[t]{3}{*}{ Total RQLQ score } & Group 1 & $2.03 \pm 0.76$ & $1.55 \pm 0.78$ & $<0.001$ \\
\hline & Group 2 & $2.33 \pm 0.69$ & $1.17 \pm 0.59$ & $<0.001$ \\
\hline & $p^{b}$ & 0.102 & 0.011 & \\
\hline
\end{tabular}

Mean $\pm S D ;{ }^{a}$ Paired samples t-test; ${ }^{b}$ Independent samples $t$-test; bold $p$-values indicate statistical significance based on Holm-Bonferonni adjustment for multiple testing. Group 1: Intranasal beclomethasone dipropionate therapy. Group 2: Rhinophototherapy with intranasal beclomethasone dipropionate therapy.

When total NOSE scores were considered, no significant differences between groups were observed before treatment $(\mathrm{p}=0.268)$. However, the differences between groups after treatment were significant $(\mathrm{p}=0.001)(\mathrm{Tab} . \mathrm{IV})$. The improvement in the total NOSE scores after treatment was larger in Group 2 as compared to Group 1 [mean differences: -38.9 (95\%CI: -46.62, -30.16) vs -15.91 (95\%CI: $-21.40,-10.42)]$.

When rhinomanometry parameters were considered, although the overall group effect was statistically significant, the group and time interaction was not (Fig. 3). In Group 2 , significant differences were observed between results taken before and after treatment for inspiratory total nasal resistances $(\mathrm{p}=0.004)$ and inspiratory total nasal flow $(\mathrm{p}=0.001)($ Tab. V). However, in Group 1, no significant differences were observed in results taken before and after treatment in terms of rhinomanometry parameters.

Rhinophototherapy was generally well-tolerated. There were no side effects other than mild dryness in the nasal mucosa, which was not severe enough to stop the treatment.

Table IV. Comparison of NOSE (Nasal Obstruction Symptom Evaluation) scores before and after treatment.

\begin{tabular}{lcccc} 
& $\begin{array}{c}\text { Treatment group } \\
\text { Total NOSE score (\%) }\end{array}$ & $\begin{array}{c}\text { Before treatment } \\
\text { (mean } \pm \text { SD) }\end{array}$ & $\begin{array}{c}\text { After treatment } \\
\text { (mean } \pm \text { SD) }\end{array}$ & $p^{\text {a }}$ \\
& Group 1 & $61.67 \pm 22.00$ & $45.76 \pm 22.32$ & $<0.001$ \\
& Group 2 & $67.10 \pm 16.27$ & $28.71 \pm 14.72$ & 0.001 \\
\hline
\end{tabular}

Mean \pm SD; ${ }^{a}$ Paired samples $t$-test; ${ }^{b}$ Independent samples $t$-test; bold $p$-values indicate statistical significance based on Holm-Bonferonni adjustment for multiple testing. Group 1: Intranasal beclomethasone dipropionate therapy. Group 2: Rhinophototherapy with intranasal beclomethasone dipropionate therapy. 
Table V. Comparison of rhinomanometric parameters before and after treatment.

\begin{tabular}{|c|c|c|c|c|}
\hline & Treatment group & Before treatment (mean \pm SD) & After treatment (mean \pm SD) & $\mathrm{p}^{\mathrm{a}}$ \\
\hline \multirow{3}{*}{$\begin{array}{l}\text { İnspiratory total nasal } \\
\text { resistances }\end{array}$} & Group 1 & $0.33 \pm 0.12$ & $0.28 \pm 0.08$ & 0.018 \\
\hline & Group 2 & $0.35 \pm 0.16$ & $0.24 \pm 0.08$ & 0.004 \\
\hline & $p^{b}$ & 0.578 & 0.074 & \\
\hline \multirow[t]{2}{*}{ İnspiratory total nasal flow } & Group 1 & $516.35 \pm 144.8$ & $579.59 \pm 177.73$ & 0.042 \\
\hline & Group 2 & $516.57 \pm 158.75$ & $671.12 \pm 170.60$ & 0.001 \\
\hline
\end{tabular}

Mean $\pm S D$; ${ }^{\text {a }}$ Paired samples $t$-test; ${ }^{b}$ Independent samples $t$-test; bold $p$-values indicate statistical significance based on Holm-Bonferonni adjustment for multiple testing. Group 1: Intranasal beclomethasone dipropionate therapy. Group 2: Rhinophototherapy with intranasal beclomethasone dipropionate therapy.

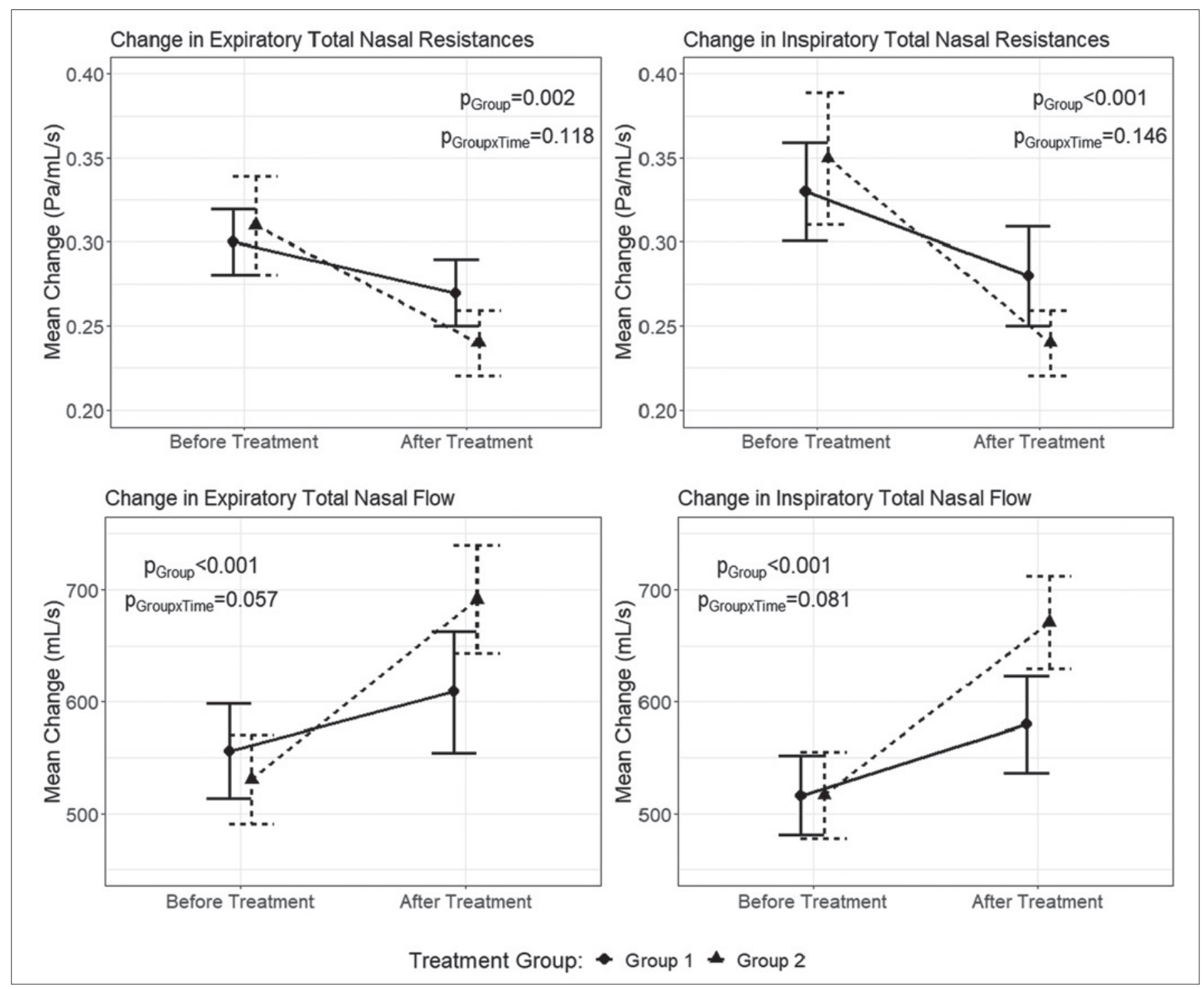

Figure 3. Changes in Rhinomanometry parameters after treatment, compared to before treatment (figures represent mean \pm SEM. $p$-values obtained from twoway repeated measures ANOVA). 


\section{Discussion}

SAR has a significant negative affect on the quality of life ${ }^{16}$. The symptom of AR that most severely impacts quality of life is nasal congestion. INCS are given as the first treatment option in international guidelines due to their effectiveness in relieving the nasal symptoms of AR. In a meta-analysis, INCS were reported to be superior to OA in improving nasal symptoms and quality of life in patients with AR ${ }^{17}$. However, many patients report that these pharmacotherapies are insufficient to control their allergic symptoms ${ }^{18}$. Therefore, alternative treatment modalities are needed. In this prospective controlled study, we showed that the addition of rhinophototherapy to intranasal beclomethasone dipropionate therapy improves quality of life and objectively improves nasal patency in patients with SAR. To our knowledge, our study is the first to demonstrate that rhinophototherapy objectively improves nasal patency.

Based on the results of their randomised double-blind controlled study, Koreck et al. ${ }^{7}$ proposed intranasal phototherapy with a combination of UVA, UVB and visible light as treatment for patients with AR who did not respond to pharmacotherapy. Various studies have shown that rhinophototherapy reduces AR symptoms and improves quality of life ${ }^{19-21}$. In these studies, the effectiveness of rhinophototherapy was evaluated with visual analog scores (VAS), Total Nasal Symptom Scores (TNSS) and RQLQ scores. However, in our study, two other measurements were used in addition to the RQLQ questionnaire: the NOSE questionnaire (which measures the effect of nasal obstruction on quality of life) and rhinomanometry (which provides an objective measurement of nasal congestion).

In their pilot study, Garaczi et al. ${ }^{19}$ compared the clinical effectiveness of rhinophototherapy with fexofenadine hydrochloride. The results were evaluated by changes in the TNSS scores and the authors reported that intranasal phototherapy was more effective than fexofenadine $\mathrm{HCl}$ in patients with SAR ${ }^{19}$.

Tatar et al. ${ }^{20}$ reported that the addition of rhinophototherapy to medical therapy (topical mometasone furoate and oral levocetirizine) had a better effect on quality of life in persistent AR than medical treatment. In a randomised, prospective, placebo-controlled study, Cingi et al. ${ }^{21}$ used TNSS scores to evaluate the efficacy of rhinophototherapy (UV-A, UV-B, visible light) in patients whose symptoms could not be controlled with pharmacotherapy; it was concluded that it was an effective method to improve disease symptoms and quality of life. The randomised, single blind, placebocontrolled study by Alyasin et al. ${ }^{22}$ showed that intranasal phototherapy with a combination of UVA, UVB and visible light therapy is an effective therapeutic procedure to treat AR. In their clinical study, Kennedy et al. ${ }^{23}$ demonstrated that intranasal phototherapy is effective in reducing nasal symptoms - but not eye symptoms - in patients with AR susceptibility to a single allergen or a combination of multiple allergens. Our study showed that nasal beclomethasone dipropionate alone did not significantly decrease eye symptoms, but, when combined with rhinophototherapy, eye symptoms were significantly decreased.

A recent meta-analysis has revealed that rhinophototherapy is more effective in reducing symptoms and improving quality of life in AR patients compared to those with perennial AR ${ }^{24}$. The authors reported that studies evaluating objective airflow parameters were required to confirm the effectiveness of phototherapy in $\mathrm{AR}^{24}$.

Albu and Baschir showed that rhinophototherapy had similar efficacy as intranasal azelastine in reducing symptoms in patients with SAR ${ }^{10}$. In their study, TNSS scores, RQLQ scores and active anterior rhinomanometry were used before and after treatment in the evaluation of patients. However, the decrease in nasal resistance was not significant after treatment in either group. In contrast, in our study, when nasal beclomethasone dipropionate treatment was applied alone, no significant decrease was observed in nasal resistance after treatment; however, when combined with rhinophototherapy, a significant reduction in nasal resistance was observed. The strength of our study is that the results are based on subjective and objective measurements that are strongly recommended in the literature. There are several limitations to this study. First of all, the physicians who applied the treatments as well as patients could not be blinded to the study design. The results were evaluated by a different researcher in order to minimise the negative consequences of this study design. Secondly, nasal resistance was measured without the use of a decongestant. Type of nasal obstruction should be determined by rhinomanometry before and after topical decongestant administration. Thirdly, environmental pollen load was not taken into consideration. The possible difference in pollen counts may have affected the results as well. Another limitation of this study is that the satisfaction index of patients was not evaluated.

\section{Conclusions}

Adding intranasal phototherapy with a combination of UVA, UVB, and visible light therapy to nasal beclomethasone dipropionate treatment positively affects the quality of life and objectively improves nasal patency in patients with SAR. Our study suggests that the addition of rhinophototherapy to other medical treatments can be implemented on a large scale in the standard treatment of SAR. 


\section{Acknowledgements}

The English in this document has been checked by at least two professional editors, both native speakers of English.

\section{References}

1 Brożek JL, Bousquet J, Agache I, et al. Allergic Rhinitis and its Impact on Asthma (ARIA) guidelines-2016 revision. J Allergy Clin Immunol 2017;140:950-958. https://doi.org/10.1016/j. jaci.2017.03.050

2 Corey JP, Houser SM, Ng BA. Nasal congestion: a review of its etiology, evaluation, and treatment. Ear Nose Throat J 2000;79:690-693. https://doi.org/10.1177/014556130007900908

3 Bridgeman MB. Overcoming barriers to intranasal corticosteroid use in patients with uncontrolled allergic rhinitis. Integr Pharm Res Pract 2017;6:109-119. https://doi.org/10.2147/iprp s129544

4 Ferrante G, Montalbano L, Cilluffo G, et al. Beclomethasone dipropionate hydrofluoroalkane for the treatment of allergic rhinitis. Expert Rev Clin Immunol 2016;12:279-288. https://doi.org/10.1586/174466 6X.2016.1118347

5 Bukstein D, Parikh R, Eid S, et al. Beclomethasone dipropionate nasal aerosol in patients with perennial allergic rhinitis (BALANCE) study: 6-month results. Allergy Asthma Proc 2016;37:121-130. https://doi. org/10.2500/aap.2016.37.3939

6 Man LX. Complementary and alternative medicine for allergic rhinitis. Curr Opin Otolaryngol Head Neck Surg 2009;17:226-231. https:// doi.org/10.1097/MOO.0b013e3283295791

7 Koreck AI, Csoma Z, Bodai L, et al. Rhinophototherapy: a new therapeutic tool for the management of allergic rhinitis. J Allergy Clin Immunol 2005;115:541-547. https://doi.org/10.1016/j.jaci.2004.11.005.

8 Kemény L, Koreck A. Ultraviolet light phototherapy for allergic rhinitis. J Photochem Photobiol B 2007;87:58-65. https://doi. org/10.1016/j.jphotobiol.2007.01.001

9 Bella Z, Kiricsi Á, Viharosné ÉD, et al. Rhinophototherapy in persistent allergic rhinitis. Eur Arch Otorhinolaryngol 2017;274:15431550. https://doi.org/10.1007/s00405-016-4358-x

10 Albu S, Baschir S. Intranasal phototherapy versus azelastine in the treatment of seasonal allergic rhinitis. Auris Nasus Larynx 2013;40:447-451. https://doi.org/10.1016/j.anl.2012.10.005

11 Juniper EF, Thompson AK, Ferrie PJ, et al. Validation of the standardized version of the Rhinoconjunctivitis Quality of Life Questionnaire. J Allergy Clin Immunol 1999;104:364-369. https://doi.org/10.1016/ S0091-6749(99)70380-5

12 Kahveci OK, Miman MC, Yucel A, et al. The efficiency of Nose Obstruction Symptom Evaluation (NOSE) scale on patients with nasal septal deviation. Auris Nasus Larynx 2012;39:275-279. https://doi. org/10.1016/j.anl.2011.08.006

13 Stewart MG, Witsell DL, Smith TL, et al. Development and validation of the Nasal Obstruction Symptom Evaluation (NOSE) scale. Otolaryngol Head Neck Surg 2004;130:157-163. https://doi.org/10.1016/j. otohns.2003.09.016

14 Lu J, Han D, Zhang L. Accuracy evaluation of a numerical simulation model of nasal airflow. Acta Otolaryngol 2014;134:513-519. https:// doi.org/10.3109/00016489.2013.863430

15 Walter W, Sánchez-Cabo F, Ricote M. GOplot: an R package for visually combining expression data with functional analysis. Bioinformatics 2015;31:2912-2914. https://doi.org/10.1093/bioinformatics/ btv300

16 Craig TJ, McCann JL, Gurevich F, et al. The correlation between allergic rhinitis and sleep disturbance. J Allergy Clin Immunol 2004;114:S139-145. https://doi.org/10.1016/j.jaci.2004.08.044

17 Juel-Berg N, Darling P, Bolvig J, et al. Intranasal corticosteroids compared with oral antihistamines in allergic rhinitis: a systematic review and meta-analysis. Am J Rhinol Allergy 2017;31:19-28. https://doi. org/10.2500/ajra.2016.30.4397

18 Larsen JN, Broge L, Jacobi H. Allergy immunotherapy: the future of allergy treatment. Drug Discov Today 2016; 21:26-37. https://doi. org/10.1016/j.drudis.2015.07.010

19 Garaczi E, Boros-Gyevi M, Bella Z, et al. Intranasal phototherapy is more effective than fexofenadine hydrochloride in the treatment of seasonal allergic rhinitis: results of a pilot study. Photochem Photobiol 2011;87:474-477. https://doi.org/10.1111/j.1751-1097.2010.00882.x

20 Tatar EÇ, Korkmaz H, Sürenoğlu UA, et al. Effects of rhinophototherapy on quality of life in persistant allergic rhinitis. Clin Exp Otorhinolaryngol 2013;6:73-77. https://doi.org/10.3342/ceo.2013.6.2.73

21 Cingi C, Cakli H, Yaz A, et al. Phototherapy for allergic rhinitis: a prospective, randomized, single-blind, placebo-controlled study. Ther Adv Respir Dis 2010;4:209-213. https://doi. org/10.1177/1753465810374610

22 Alyasin S, Nabavizadeh SH, Houshmand H, et al. Short time efficiency of rhinophototherapy in management of patients with allergic rhinitis resistant to medical therapy. Iran J Allergy Asthma Immunol 2016;15:317-327.

23 Kennedy R, Robertson L. Study on the effect of phototherapy for inhibition of symptoms associated with allergic rhinitis. Eur Ann Allergy Clin Immunol 2020;52:66-73. https://doi.org/10.23822/EurAnnACI.1764-1489.111

24 Cho HK, Jeong YM, Lee HS, et al. Efficacy of endonasal phototherapy for relieving the symptoms of allergic rhinitis: meta-analysis. Am J Rhinol Allergy 2015;29:283-291. https://doi.org/10.2500/ ajra.2015.29.4190 